\title{
TIME-VARYING EQUITY PREMIUM FORECASTS BASED ON INDUSTRY INDEXES
}

\section{NUNO SILVA ${ }^{*}$}

1. Universidade de Coimbra, Coimbra, Portugal

* Corresponding Author: Nuno Silva, CeBER - Centre for Business and Economics Research, Office Room 414, Faculdade de Economia, Universidade de Coimbra, Av. Dr. Dias da Silva, 165, 3004-512 COIMBRA, PORTUGAL

甶 ++351239790545凶nunos@fe.uc.pt or nmbgs2@hotmail.com

\begin{abstract}
:
Various studies report that the ability of industry indexes to predict the broad market disappeared during the most recent years. I revisit this theme using more flexible switching models and imposing economically motivated constraints on the predictions. My results show that traditional constant coefficients linear models are unable to forecast the stock market over the period considered, but restricting the equity premium to be non-negative, five industries predict the market. I also show that the Markov-switching models exhibit a dismal performance, which is even worse than the ones from the constant coefficients model. Finally, I test a model with two regimesrecession and expansion- which are identified in real-time through the AroubaDiebold-Scotti Business Conditions Index. Using this model, I find that 8 out of 33 industries can successfully forecast the market. Furthermore, a mean-variance investor who bases his decisions on it obtains sizeable utility gains, relative to another investor who uses, exclusively, the historical returns.
\end{abstract}

Keywords: Equity premium forecasts, Industry indexes, Regime switch, Portfolio choice JEL classification: C58, G11, G17

\section{Introduction}

It is a known fact that investors' time and resources to process information is limited. Hong et al. (2007) draw on this issue to show that information flows slowly across industries, which implies that industry returns can predict the broad market returns. They find that 14 of 34 U.S. industry indexes returns possess the ability to predict the market over the period January 1946-December 2002. These results were contested by Tse (2015) and Ponka (2015), who argue that predictability disappears when the analysis is expanded to include the most recent years.

In this study, I revisit the theme of industry-based equity premium predictability. I aim to find if predictability disappeared, or if it has become time-varying in nature. To accomplish this goal, I consider both Markov switching models and a method that identifies recession states based on the observable Arouba-Diebold-Scotti (ADS) Business Conditions Index (see, Arouba et al. 2009), as in Sander (2018).

My contribution to the literature is twofold. First, I show that the ADS switching model uncovers the ability of several industries to predict the broad market, which is not 
apparent in the simple linear model. Second, I combine this method with economically motivated non-negativity restrictions on the equity premium and find a notorious improvement in forecasts during expansions.

My results reveal the ADS method markedly improves the equity premium forecasts relative to the simple linear and the Markov switching models. I find that 8 out of 32 industries can predict the market in the ADS model, and none in other ones. I also show that forecast combinations based on the ADS model generate positive out-of-sample $R$-squared and sizable utility gains for a mean-variance investor.

\section{Literature Review}

Several studies explore the slow diffusion of information across markets to forecast the equity premium. Hong et al. (2007) show that industry returns lead the market by up to two months. The statistical and economic out-of-sample performance of forecast combinations is analysed in Silva (2018), who finds that these combinations generate significant R-squared and sizable economic gains for a mean-variance investor. Using an updated version of Hong et al. (2008) database, Tse (2015) shows that industries do not lead the market, but the reverse causality holds for several industries. Probit models are used to forecast the direction of the US stock market, based on industry returns, in Ponka (2016). The author shows that these models outperform simple linear models and improve investment returns. Jacobsen et al. (2018) report that industrial metal returns lead the stock market, even after controlling for some other commonly used predictors. They also show that there is a direct relation between the stock market returns and past industrial metal returns during recessions, and an inverse one in expansionary periods.

The predictability of industry returns is addressed in Menzly and Ozbas (2010), who show that industries related through the supply chain present significant cross-momentum. Hou (2007) finds large firms transmit shocks to small firms in the same industry, and the former returns' lead the latter ones. Using a machine learning approach, Rapach et al. (2019) report that lagged returns for the financial sector and commodity and materialproducing industries have forecasting ability for most industries. They also show an investment strategy that goes long the industries with the largest forecasted returns and short the industries with the lowest ones generates an annualized alpha higher than $8 \%$.

The effect of technological closeness on stock returns is analyzed in Lee et al. (2019). The authors show that firms whose peer group exhibited a positive return in the past month outperform the ones whose peer group return was negative.

The issue of the instability in equity premium predictive models is a common concern amongst financial researchers. Baetje and Menkhoff (2016) report that equity premium forecasts based on technical indicators are stable, but those based on economic indicators are not. A frequent choice to model predictive instability is Markov switching models, such as in Henkel et al. (2012) and Zhu and Zhu (2012). Both authors find that regime-switching models outperform the traditional linear model and deliver consistent out-of-sample forecasting gains. Furthermore, they show that predictability is mainly present in recessions. Guidolin and Hyde (2012) find that a simple three-state Markov switching model delivers a higher certainty equivalent return than more complex VAR models. Sander (2018) follows an alternative approach and identifies the recession state in the economy through observable dummies, based either on the ADS Business Confidence Indicator or the Purchasing Managers' Index. He shows that this model performs significantly better than a simple Markov-switching one and provides significant certainty equivalent return gains relative to the no predictability benchmark. 
An alternative form to model the variability in predictive coefficients is through dynamic linear models that, unlike Markov-switching models, generate smoothly changing coefficients. This is the approach adopted in Dangl and Halling (2012) to forecast the monthly returns of the S\&P 500. The authors find that models with time-varying coefficients dominate constant coefficients ones and, deliver relevant economic gains for a mean-variance investor.

\section{Methodology}

\subsection{Model Specification and Estimation Method}

The prior evidence on equity premium forecast instability has motivated me to compare the predictive performance of a traditional constant coefficients model with two timevarying ones. The first model is specified as follows

$$
R_{t}=\alpha+\beta I_{t-1}+\varepsilon_{t}
$$

where $R_{t}$ is the equity premium in month $t \mathrm{I}_{\mathrm{t}-1}$ is the excess return of the industry over the riskless rate in month $t-1$, and $\varepsilon+$ is a normal error.

The first time-varying model that I estimate is a standard, two-state, Markov-switching model

$$
R_{t}=\alpha\left(s_{t}\right)+\beta\left(s_{t}\right) I_{t}+\varepsilon\left(s_{t}\right)
$$

where $s_{t} \in\{1,2\}$ represents the state, and the transition probabilities are constant. I follow Henkel et al. (2011) and achieve identification by assuming that the residual volatility is higher in the second regime.

I also consider another switching model that is based on the state of the economy. The most commonly used business cycle classifier in the US is the National Bureau of Economic Research (NBER) one. However, the recession dates are only available with a significant lag, which prevents their direct use in a forecasting model. To circumvent this problem, I follow Berge and Jorda (2011) and Sander (2018) and use the AroubaDiebold-Scotti Business Conditions Index' (ADS) to generate a dummy variable that identifies recessions. Specifically, I use the Receiver Operating Characteristic (ROC) curve to find the thresholds that maximize the ability to correctly identify NBER recessions. Let TP(c) and FP(c) represent the true and false positive identification rates for recessions, respectively

$$
T P(c)=P\left[A D S_{t} \geq c \mid N B E R=0\right]
$$

\footnotetext{
1 The Arouba-Diebold-Scotti Business Conditions Index is an indicator designed to assess economic activity in real-time. It used a dynamic factor model to filter economic information from various sources.
} 


$$
F P(c)=P\left[A D S_{t} \geq c \mid N B E R=1\right]
$$

where NBER is a dummy variable that assumes the value 0 (1) during recession (expansion) months and $\mathrm{c}$ is the threshold. I obtain the optimal threshold by solving the following maximization problem in each month

$$
\max _{c}(2 \hat{\pi} \widehat{T P}(c)-\hat{\pi})-(2(1-\hat{\pi}) \widehat{F P}(c)-(1-\hat{\pi}))
$$

where $\pi$ is the unconditional recession probability, and the variables with a hat are sample estimates of the ones without a hat. Since NBER recession dates are not available in real-time, I estimate the threshold for month t using only the data up to month t-3, as in Sander (2018).

I employ Gibbs sampling, with uninformative priors, to estimate all the models. For each model, I consider two versions: the first one has no restrictions, and, in the second one, I impose the condition that the expected equity premium must be non-negative. Several authors, such as Campbell and Thompson (2008), Pastor and Stambaugh (2009, 2012), and Pettenuzzo et al. (2014), reveal that parameter restrictions improve equity premium predictions. In this study, I follow Pettenuzzo et al. (2014) and apply a rejection step in the Gibbs sampling algorithm. That is, I reject the draws that generate a negative equity premium prediction for any time up to the estimation month, in the constant parameter models. In the time-varying models, this restriction is applied separately for each state. Note that this procedure is more efficient than the one used in Campbell and Thompson (2008), that merely truncates negative equity premium forecasts, and does not allow this information to alter their estimated coefficients.

I also examine the performance of forecast combinations based on individual models. Past research, such as Pettenuzzo and Ravazzolo (2016), Rapach et al. (2010), Dangl and Halling (2012), and Avramov (2002), show this method generates smoother and more precise predictions than the ones based on single predictors. In this study, I analyze the performance of the following forecast combinations, for each model: simple average, median and weighted average based on the inverse of the meansquared prediction error, as in Rapach et al. (2010).

\subsection{Performance Evaluation}

The forecasts, based on the method described above, are obtained by estimating the model recursively, using an expanding window. That is, I estimate the model with data up to month $\dagger$ to obtain an equity premium forecast for month $t+1$. Then, I add another month and re-estimate the model to get the $t+2$ equity premium forecast. This procedure is repeated until the end of the sample.

I use the pseudo R-squared out-of-sample to measure the predictive accuracy of the individual model and combined forecasts 


$$
R_{\text {oos }}^{2}=1-\frac{M S P E_{\text {mod }}}{M S P E_{\text {hist }}}
$$

, where $M S P E_{\text {mod }}$ is the mean-squared prediction error over the out-of-sample period based on the model, and $M S P E_{\text {hist }}$ represents the mean-squared prediction error computed from the equity premium historical average. The statistical significance of the prediction is tested through the MSPE-adjusted statistic, developed by Clark and West (2007). This test is an approximately normal modification of the McCraken (2007) MSE-F statistic. According to its null hypothesis, the unrestricted and restricted models possess equal forecasting ability, while, under the alternative hypothesis, the former exhibits a lower MSPE than the later. A simple way to implement this test is to compute

$$
\hat{\mathrm{f}}_{\mathrm{t}}=\left(\mathrm{R}_{\mathrm{t}}-\mathrm{R}_{\mathrm{t}}^{\mathrm{hist}}\right)^{2}-\left[\left(\mathrm{R}_{\mathrm{t}}-\mathrm{R}_{\mathrm{t}}^{\mathrm{mod}}\right)^{2}-\left(\mathrm{R}_{\mathrm{t}}^{\mathrm{hist}}-\mathrm{R}_{\mathrm{t}}^{\mathrm{mod}}\right)^{2}\right]
$$

, where $R_{t}^{\text {hist }}$ and $R_{t}^{\text {mod }}$ represent the equity premium forecasts based on the historical average and the model, respectively. The MSPE-adjusted statistic is calculated by regressing $\hat{f}_{t}$ on a constant. The null hypothesis of equal predictive ability is rejected at the $5 \%$ level if the resulting t-statistic exceeds 1.645 (one-sided test).

I assess the economic value of the forecast combinations by comparing the realized utility for an investor who uses these predictions to support his investment decisions, with the utility an investor would get if he relied, exclusively, on the historical average returns. The fraction of wealth invested in the stock market2, at month t, for an investor with a coefficient of relative risk aversion $\gamma$, who uses the forecasts based on model combinations is

$$
\mathrm{w}_{\mathrm{t}}^{\mathrm{mod}}=\frac{1}{\gamma} \frac{\widehat{\mathrm{R}}_{\mathrm{t}+1}^{\mathrm{mod}}}{\widehat{\sigma}_{\text {mod,t+1 }}^{2}}
$$

, where $\hat{R}_{t+1}^{\text {mod }}$ and $\hat{\sigma}_{m o d, t+1}^{2}$ represent the expected equity premium and variance based on the model combination. An individual who uses only historical information to drive his investment strategy chooses

\section{Data}

I extracted from Ken French's website the monthly returns on 38 value-weighted industry portfolios for the period comprised between March 1960 and the end of 2018. Six industries- agriculture, forestry and fishing, sanitary services, steam supply, irrigation systems, public administration, and other- were dropped due to missing data. I also obtained, from this website, the one-month Treasury bill rate (risk-free rate) and the excess return over the risk-free rate on the market value-weighted return of all the CRSP firms incorporated in the US and listed on the NYSE, AMEX, Or NASDAQ (equity premium) for the same period.

\footnotetext{
2 I follow Campbell and Thompson (2008) and assume that the fraction of wealth invested in stocks can neither exceed $150 \%$ nor be negative.
} 
The monthly series of the Arouba-Diebold-Scotti (ADS) Business Conditions Index and the NBER recessions indicator are from the Federal Reserve Bank of Philadelphia and the NBER websites, respectively.

Table 1: Descriptive statistics for the equity premium (EP) and the 32 industries' monthly returns.

\begin{tabular}{ccccccccc}
\hline Industry & Mean & Std & Industry & Mean & Std & Industry & Mean & Std \\
\hline EP & $0.52 \%$ & $4.38 \%$ & PAPER & $0.48 \%$ & $5.48 \%$ & CARS & $0.59 \%$ & $5.60 \%$ \\
MINES & $0.57 \%$ & $8.05 \%$ & PRINT & $0.48 \%$ & $5.76 \%$ & INSTR & $0.58 \%$ & $5.20 \%$ \\
OIL & $0.58 \%$ & $7.27 \%$ & CHEMS & $0.57 \%$ & $4.44 \%$ & MANUF & $0.44 \%$ & $6.66 \%$ \\
STONE & $0.79 \%$ & $7.81 \%$ & PTRLM & $0.69 \%$ & $5.04 \%$ & TRANS & $0.58 \%$ & $5.74 \%$ \\
CNSTR & $0.55 \%$ & $7.18 \%$ & RUBBER & $0.62 \%$ & $5.88 \%$ & PHONE & $0.41 \%$ & $4.80 \%$ \\
FOOD & $0.70 \%$ & $4.32 \%$ & LETHR & $0.77 \%$ & $5.25 \%$ & TV & $0.90 \%$ & $6.41 \%$ \\
SMOKE & $0.93 \%$ & $6.08 \%$ & GLASS & $0.51 \%$ & $6.72 \%$ & UTILS & $0.48 \%$ & $3.96 \%$ \\
TXTLS & $0.62 \%$ & $7.07 \%$ & METAL & $0.28 \%$ & $7.26 \%$ & WHLSL & $0.60 \%$ & $5.67 \%$ \\
APPRL & $0.57 \%$ & $6.71 \%$ & MTLPR & $0.66 \%$ & $5.33 \%$ & RTAIL & $0.69 \%$ & $5.25 \%$ \\
WOOD & $0.59 \%$ & $7.74 \%$ & MACHN & $0.58 \%$ & $6.34 \%$ & MONEY & $0.61 \%$ & $5.38 \%$ \\
CHAIR & $0.57 \%$ & $6.52 \%$ & ELCTR & $0.61 \%$ & $6.73 \%$ & SRVC & $0.72 \%$ & $6.38 \%$ \\
\hline
\end{tabular}

Table 1 presents the mean and standard deviation of the industry monthly excess returns over the risk-free rate, and the equity premium. The average monthly equity premium over the period considered was $0.52 \%$, and its standard deviation was $4.38 \%$. The industry exhibiting the highest average monthly return was smoke $(0.93 \%)$, and metal $(0.28 \%)$ had the lowest one. The standard deviations range between $3.96 \%$ for utilities and $8.05 \%$ for mines.

\section{Results}

In this section, I present and discuss the main out-of-sample results, which cover the period comprised between January 1990 and December 2018. The out-of-sample period starts, approximately, 20 years after the beginning of the sample because it is essential to have a sizable number of observations to obtain reliable parameter forecasts.

Table 2 shows the R-squared out-of-sample for all the models. In the unrestricted version of the constant coefficients model, most R-squared are negative (22 out of 33), and none is statistically significant. Imposing the constraint that equity premia cannot be negative improves the forecasts: all the R-squared become positive and 5 are significant at the $10 \%$ level (Chair, Phone, TV, Utilities, and Money). The Markov-switching model delivers disappointing results. All the R-squared are negative in the unrestricted model, and, in the restricted one, the R-squared fluctuate around zero. The ADS model without restrictions is the best performing one. Eighteen out of thirty-three R-squared are positive, and there is statistical evidence of predictability at the $5 \%$ level for Chair and Retail, and at the $10 \%$ level for Apparel, Glass, Machinery, Transport, TV, and Money. In this model, requiring that equity premia are non-negative leads to a deterioration in predictive ability.

Table 3 decomposes the predictive ability of the best performing model between periods classified as expansions and recessions, according to the Arouba-Diebold-Scotti Business Conditions Index. In the unrestricted model, predictability is concentrated mostly during recessions, which is consistent with Sander (2018). Several industries, such as Rubber, Retail, and Money, exhibit R-squared values higher than 3\%, and 10 out of the 33 Rsquared are statistically significant. During expansions, no industry can forecast the equity 
premium. Curiously, the restriction of non-negativity for the equity premium destroys the forecasting ability of this model in recessions but markedly improves its performance during expansions. All R-squared for the restricted model are positive during expansions, and eleven are statistically significant.

Table 2

\begin{tabular}{|c|c|c|c|c|c|c|}
\hline & \multicolumn{2}{|c|}{ No Switch } & \multicolumn{2}{|c|}{ MS Switch } & \multicolumn{2}{|c|}{ ADS Switch } \\
\hline & Un & Res & Un & Res & Un & Res \\
\hline MINES & $-0.53 \%$ & $0.1 \%$ & $-1.73 \%$ & $-0.14 \%$ & $-1.19 \%$ & $-0.17 \%$ \\
\hline OIL & $-0.43 \%$ & $0.07 \%$ & $-2.27 \%$ & $-0.19 \%$ & $-0.69 \%$ & $-0.15 \%$ \\
\hline STONE & $-0.08 \%$ & $0.09 \%$ & $-1.17 \%$ & $-0.04 \%$ & $-0.04 \%$ & $-0.13 \%$ \\
\hline CNSTR & $-0.28 \%$ & $0.14 \%$ & $-1.15 \%$ & $-0.08 \%$ & $0.01 \%$ & $-0.03 \%$ \\
\hline FOOD & $-0.59 \%$ & $0.14 \%$ & $-1.52 \%$ & $-0.08 \%$ & $0.33 \%$ & $-0.03 \%$ \\
\hline SMOKE & $-1.07 \%$ & $0.06 \%$ & $-1.81 \%$ & $-0.13 \%$ & $-3.46 \%$ & $-0.51 \%$ \\
\hline TXTLS & $-0.96 \%$ & $0.15 \%$ & $-1.74 \%$ & $-0.08 \%$ & $-0.97 \%$ & $-0.06 \%$ \\
\hline APPRL & $-0.36 \%$ & $0.18 \%$ & $-0.92 \%$ & $-0.01 \%$ & $0.71 \% \mathrm{~b}$ & $0.05 \%$ \\
\hline WOOD & $-0.57 \%$ & $0.1 \%$ & $-1.29 \%$ & $-0.06 \%$ & $0.04 \%$ & $0.01 \%$ \\
\hline CHAIR & $0.41 \%$ & $0.23 \%$ b & $-0.72 \%$ & $-0.06 \%$ & $0.78 \%$ & $-0.14 \%$ \\
\hline PAPER & $-0.55 \%$ & $0.09 \%$ & $-1.46 \%$ & $-0.11 \%$ & $-0.83 \%$ & $-0.16 \%$ \\
\hline PRINT & $-0.71 \%$ & $0.26 \%$ & $-0.78 \%$ & $-0.02 \%$ & $0 \%$ & $-0.03 \%$ \\
\hline CHEMS & $0.09 \%$ & $0.18 \%$ & $-1.32 \%$ & $-0.04 \%$ & $0.28 \%$ & $0.03 \%$ \\
\hline PTRLM & $-0.13 \%$ & $0.11 \%$ & $-1.63 \%$ & $-0.06 \%$ & $-0.52 \%$ & $-0.11 \%$ \\
\hline RUBBER & $0.03 \%$ & $0.14 \%$ & $-0.80 \%$ & $-0.11 \%$ & $1.71 \% a$ & $0.24 \%$ \\
\hline LETHR & $-0.63 \%$ & $0.27 \%$ & $-1.81 \%$ & $-0.06 \%$ & $0.24 \%$ & $0.01 \%$ \\
\hline GLASS & $-0.41 \%$ & $0.12 \%$ & $-0.85 \%$ & $-0.01 \%$ & $0.81 \% \mathrm{~b}$ & $0.19 \%$ \\
\hline METAL & $-0.49 \%$ & $0.1 \%$ & $-1.90 \%$ & $-0.15 \%$ & $-0.52 \%$ & $-0.04 \%$ \\
\hline MTLPR & $-0.73 \%$ & $0.12 \%$ & $-1.14 \%$ & $-0.01 \%$ & $0.67 \%$ & $0.01 \%$ \\
\hline MACHN & $-0.01 \%$ & $0.17 \%$ & $-0.74 \%$ & $-0.01 \%$ & $0.98 \% \mathrm{~b}$ & $0.03 \%$ \\
\hline ELCTR & $0.42 \%$ & $0.23 \%$ & $-0.62 \%$ & $-0.18 \%$ & $0.23 \%$ & $-0.13 \%$ \\
\hline CARS & $-0.69 \%$ & $0.12 \%$ & $-1.15 \%$ & $-0.08 \%$ & $-0.77 \%$ & $-0.16 \%$ \\
\hline INSTR & $-0.27 \%$ & $0.13 \%$ & $-1.28 \%$ & $0 \%$ & $-0.21 \%$ & $-0.09 \%$ \\
\hline MANUF & $-0.64 \%$ & $0.11 \%$ & $-1.2 \%$ & $0.01 \%$ & $-0.28 \%$ & $-0.05 \%$ \\
\hline TRANS & $0.02 \%$ & $0.18 \%$ & $-0.84 \%$ & $-0.07 \%$ & $1.12 \% \mathrm{~b}$ & $0.19 \%$ \\
\hline PHONE & $0.33 \%$ & $0.43 \%$ b & $-1.52 \%$ & $-0.04 \%$ & $-1.23 \%$ & $-0.11 \%$ \\
\hline TV & $0.33 \%$ & $0.43 \%$ b & $-0.36 \%$ & $0.15 \%$ & $0.68 \% \mathrm{~b}$ & $0 \%$ \\
\hline UTILS & $0.17 \%$ & $0.38 \%$ b & $-0.63 \%$ & $0.09 \%$ & $0.34 \%$ & $0.03 \%$ \\
\hline WHLSL & $-0.16 \%$ & $0.16 \%$ & $-0.87 \%$ & $-0.03 \%$ & $-0.14 \%$ & $-0.09 \%$ \\
\hline RTAIL & $-0.03 \%$ & $0.21 \%$ & $-0.28 \%$ & $0.04 \%$ & $1.33 \% a$ & $0.15 \%$ \\
\hline MONEY & $0.09 \%$ & $0.36 \%$ b & $-0.76 \%$ & $0.09 \%$ & $1.29 \% \mathrm{~b}$ & $0.05 \%$ \\
\hline SRVC & $0.01 \%$ & $0.24 \%$ & $-0.66 \%$ & $0.05 \%$ & $0.45 \%$ & $-0.02 \%$ \\
\hline
\end{tabular}

R-squared out-of-sample for the constant coefficients model (No Switch), the Markov-switching model (MS Switch), and the switching model based on the ADS Business Conditions Index (ADS). For each model, the first column (Un) displays the R-squared out-of-sample for the unrestricted model, and the second one (Res) exhibits the R-squared based on estimations that impose non-negative equity premia.

a- Significant at $5 \%$, b- significant at $10 \%$.

Tables 4 and 5 display the statistical and economic performance of the predictions based on combinations of forecasts from the individual models. All the models deliver negative out-of-sample R-squared, except the unrestricted ADS one. For this last model, all the R-squared are positive, irrespective of the combination method chosen. The weighted average generates the highest R-squared $(0.41 \%)$, and the median the lowest one. 
Table 5 shows that all the models deliver positive utility gains for a mean-variance investor, whose coefficient of relative risk aversion equals 3 . The most successful one is the unrestricted ADS model, followed by the restricted ADS model. Both Markov-switching models provide low benefits for this investor. The utility gains are not very sensitive to the combination method chosen but vary markedly across model types.

Table 3

\begin{tabular}{lcccc}
\hline & \multicolumn{2}{c}{ Expansion } & \multicolumn{2}{c}{ Recession } \\
\cline { 2 - 5 } Un & Res & Un & Res \\
\hline MINES & $-0.49 \%$ & $0.68 \%$ & $-1.78 \%$ & $-0.9 \%$ \\
OIL & $-0.47 \%$ & $0.55 \%$ & $-0.86 \%$ & $-0.74 \%$ \\
STONE & $1.04 \% \mathrm{~b}$ & $0.58 \%$ & $-0.97 \%$ & $-0.73 \%$ \\
CNSTR & $-0.63 \%$ & $0.60 \%$ & $0.55 \%$ & $-0.56 \%$ \\
FOOD & $0.31 \%$ & $0.75 \% \mathrm{~b}$ & $0.34 \%$ & $-0.69 \%$ \\
SMOKE & $-2.27 \%$ & $0.24 \%$ & $-4.47 \%$ & $-1.15 \%$ \\
TXTLS & $-0.78 \%$ & $0.72 \% \mathrm{~b}$ & $-1.13 \%$ & $-0.72 \%$ \\
APPRL & $-0.76 \%$ & $0.69 \% \mathrm{~b}$ & $1.95 \% \mathrm{~b}$ & $-0.49 \%$ \\
WOOD & $-0.41 \%$ & $0.66 \%$ & $0.43 \%$ & $-0.55 \%$ \\
CHAIR & $-1.04 \%$ & $0.44 \%$ & $2.34 \% \mathrm{~b}$ & $-0.64 \%$ \\
PAPER & $-0.12 \%$ & $0.67 \%$ & $-1.44 \%$ & $-0.87 \%$ \\
PRINT & $-2.68 \%$ & $0.36 \%$ & $2.29 \% \mathrm{~b}$ & $-0.36 \%$ \\
CHEMS & $-0.09 \%$ & $0.70 \% \mathrm{~b}$ & $0.59 \%$ & $-0.54 \%$ \\
PTRLM & $-0.06 \%$ & $0.59 \%$ & $-0.91 \%$ & $-0.70 \%$ \\
RUBBR & $-0.32 \%$ & $0.83 \% \mathrm{~b}$ & $3.44 \% \mathrm{a}$ & $-0.25 \%$ \\
LETHR & $0.53 \%$ & $0.94 \% \mathrm{~b}$ & $-0.02 \%$ & $-0.78 \%$ \\
GLASS & $-0.52 \%$ & $0.82 \% \mathrm{~b}$ & $1.94 \% \mathrm{~b}$ & $-0.34 \%$ \\
METAL & $-0.66 \%$ & $0.66 \%$ & $-0.40 \%$ & $-0.63 \%$ \\
MTLPR & $-0.52 \%$ & $0.75 \% \mathrm{~b}$ & $1.68 \%$ & $-0.62 \%$ \\
MACHN & $-0.74 \%$ & $0.6 \%$ & $2.45 \% \mathrm{~b}$ & $-0.44 \%$ \\
ELCTR & $-1.40 \%$ & $0.41 \%$ & $1.62 \%$ & $-0.58 \%$ \\
CARS & $-1.16 \%$ & $0.52 \%$ & $-0.44 \%$ & $-0.74 \%$ \\
INSTR & $-0.27 \%$ & $0.63 \%$ & $-0.15 \%$ & $-0.7 \%$ \\
MANUF & $0.28 \%$ & $0.78 \% \mathrm{~b}$ & $-0.75 \%$ & $-0.76 \%$ \\
TRANS & $-0.24 \%$ & $0.75 \% \mathrm{~b}$ & $2.28 \% \mathrm{~b}$ & $-0.30 \%$ \\
PHONE & $-1.29 \%$ & $0.41 \%$ & $-1.18 \%$ & $-0.55 \%$ \\
TV & $-1.95 \%$ & $0.42 \%$ & $2.92 \% \mathrm{~b}$ & $-0.36 \%$ \\
UTILS & $0.52 \%$ & $0.71 \% \mathrm{~b}$ & $0.19 \%$ & $-0.55 \%$ \\
WHLSL & $-0.17 \%$ & $0.60 \%$ & $-0.12 \%$ & $-0.68 \%$ \\
RTAIL & $-1.22 \%$ & $0.5 \%$ & $3.5 \% \mathrm{a}$ & $-0.16 \%$ \\
MONEY & $-1.25 \%$ & $0.38 \%$ & $3.45 \% \mathrm{a}$ & $-0.23 \%$ \\
SRVC & $0.23 \%$ & $0.56 \%$ & $0.65 \%$ & $-0.52 \%$ \\
\hline R-SAO & & & \\
\hline
\end{tabular}

R-squared out-of-sample for the unrestricted (Un) and restricted (Res) ADS models, during periods classified as recession and expansion, according to the Arouba-Diebold-Scotti Business Conditions Index.

a- Significant at $5 \%$, b- significant at $10 \%$. 
Table 4

\begin{tabular}{lcccccc} 
& \multicolumn{2}{c}{ No Switch } & \multicolumn{2}{c}{ MS Switch } & \multicolumn{2}{c}{ ADS Switch } \\
\cline { 2 - 7 } & Un & Res & Un & Res & Un & Res \\
\hline Weighted & $-0.19 \%$ & $-0.09 \%$ & $-1.15 \%$ & $-0.31 \%$ & $0.41 \%$ & $-0.31 \%$ \\
Simple & $-0.21 \%$ & $-0.09 \%$ & $-1.16 \%$ & $-0.31 \%$ & $0.38 \%$ & $-0.31 \%$ \\
Median & $-0.23 \%$ & $-0.12 \%$ & $-1.10 \%$ & $-0.30 \%$ & $0.34 \%$ & $-0.30 \%$ \\
\hline
\end{tabular}

R-squared out-of-sample for forecast combinations from the constant coefficients model (No Switch), the Markov-switching model (MS Switch), and the switching model based on the ADS Business Conditions Index (ADS), using the weighted average (Weighted), the simple average (Simple), and the median (Median).

Table 5

\begin{tabular}{lcccccc}
\hline & \multicolumn{2}{c}{ No Switch } & \multicolumn{2}{c}{ MS Switch } & \multicolumn{2}{c}{ ADS Switch } \\
\cline { 2 - 7 } & Un & Res & Un & Res & Un & Res \\
\hline Weighted & $1.20 \%$ & $1.28 \%$ & $0.28 \%$ & $0.69 \%$ & $3.46 \%$ & $2.43 \%$ \\
Simple & $1.16 \%$ & $1.28 \%$ & $0.28 \%$ & $0.69 \%$ & $3.42 \%$ & $2.42 \%$ \\
Median & $1.11 \%$ & $1.19 \%$ & $0.34 \%$ & $0.65 \%$ & $3.46 \%$ & $2.44 \%$ \\
\hline
\end{tabular}

Annualized utility gains for forecast combinations from the constant coefficients model (No Switch), the Markovswitching model (MS Switch), and the switching model based on the ADS Business Conditions Index (ADS), using the weighted average (Weighted), the simple average (Simple), and the median (Median).

\section{Conclusion}

In this study, I show that traditional linear constant coefficients models, using industry indexes, can no longer predict the broad market. My results also reveal that imposing an economic motivated non-negativity constraint on the equity premium improves the forecasts. Markov-switching models fail to improve the forecasting ability of industry indexes because they cannot identify accurately the regimes in real-time.

I consider another model that identifies expansionary and recessionary regimes, in realtime, based on the Arouba-Diebold-Scotti Business Conditions Index. Using this model, 8 out of 33 industry indexes predict the market out-of-sample. The predictive ability is concentrated, essentially, during recession periods, which is coherent with past studies. Curiously, imposing a non-negativity restriction on the equity premium improves the predictions substantially during expansions, but not in recessions. It would be interesting to test if this pattern also holds when a different set of predictors is considered. I also show the forecast combinations based on the ADS model provide sizable utility gains for a mean-variance investor, which are higher than the ones from the other models.

These results are compatible with the investors' inattention hypothesis, which states they lack the time and resources to thoroughly study all the different markets. Thus, the news does not flow swiftly, and some industries lead the market. This effect is particularly notorious during recessions when several industries exhibit sizable out-of-sample Rsquared for the unrestricted model. Therefore, investors should be attentive to signals coming from these industries that may anticipate a turning point in the broad market tendency. 


\section{References}

Arouba, S. Borogan, Diebold, Francis X., \& Scotti, Chiara (2009). Real-time measurement of business conditions. Journal of Business \& Economic Statistics 27(4), 417-427. https://doi.org/10.1198/jbes.2009.07205

Avramov, Doron (2002). Stock return predictability and model uncertainty. Journal of Financial Economics 64(3), 423-458. https://doi.org/10.1016/S0304-405X(02)00131-9

Baetje, Fabian, \& Menkhoff, Lukas (2016). Equity premium prediction: Are economic and technical indicators unstable? International Journal of Forecasting 32(4), 1193-1207. https://doi.org/10.1016/j.ijforecast.2016.02.006

Berge, Travis J., \& Òscar, Jordà (2011). Evaluating the Classification of Economic Activity into Recessions and Expansions. American Economic Journal: Macroeconomics, 3 (2), 246-77. DOI: $10.1257 / \mathrm{mac} .3 .2 .246$

Campbell, John Y. \& Thompson, Samuel B. (2008). Predicting excess stock returns out of sample: dan anything beat the historical average? Review of Financial Studies 21 (4), 1509-1531. https://doi.org/10.1093/rfs/hhm055

Clark, Todd E. \& West, Kenneth D. (2007). Approximately normal tests for equal predictive accuracy in nested models. Journal of Econometrics 138(1), 291-311. https://doi.org/10.1016/j.jeconom.2006.05.023

Dangl, Thomas, \& Halling, Michael (2012). Predictive regressions with time-varying coefficients. Journal of Financial Economics 106(1), 157-181. https://doi.org/10.1016/j.jfineco.2012.04.003

Guidolin, Massimo, \& Hyde, Stuart (2012). Can VAR models capture regime shifts in asset returns? A long-horizon strategic asset allocation perspective. Journal of Banking \& Finance 36(3), 695-716. https://doi.org/10.1016/i.jbankfin.2011.10.011

Henkel, Sam James, Martin, J. Spencer, \& Nardiri, Federico (2011). Time-varying shorthorizon predictability. Journal of Financial Economics 99(3), 560-580. https://doi.org/10.1016/j.jineco.2010.09.008

Hong, Harrison, Torous, Walter, \& Valkanov, Rossen (2007). Do Industries lead stock markets? Journal of Financial Economics, 83(2), 367-396. https://doi.org/10.1016/j.jineco.2005.09.010

Hou, Kewie (2007). Industry Information Diffusion and the Lead-Lag Effect in Stock Returns. Review of Financial Studies 20(4), $1113-1138$. https://doi.org/10.1093/revfin/hhm003

Jacobsen, Ben, Marshall, Ben R., \& Visaltanachoti, Nuttawat (2019). Stock Market Predictability and Industrial Metal Returns. Management Science 65(7), 2947-3448. https://doi.org/10.1287/mnsc.2017.2933

Lee, Charles M.C., Sun, Stephen Teng, Wang, Rongfei, \& Zhang, Ran (2019). Technological links and predictable returns. Journal of Financial Economics 132(3), 76-96. https://doi.org/10.1016/j.jfineco.2018.11.008

McCraken, Michael W. (2007). Asymptotics for the out of sample tests of Granger $\begin{array}{llll}\text { causality. Journal of } & \text { Econometrics } & \text { 719-752. }\end{array}$ https://doi.org/10.1016/j.jeconom.2006.07.020 
Menzly, Lior, \& Orbas, Oguzhan (2010). Market Segmentation and Cross-predictability of Returns. The Journal of Finance 65(4), 1555-1580. https://doi.org/10.1111/j.1540$\underline{6261.2010 .01578 . x}$

Pastor, Lubos \& Stambaugh, Robert (2009). Predictive systems: living with imperfect predictors. The Journal of Finance 64(4), 1583-1628. https://doi.org/10.1111/j.1540$\underline{6261.2009 .01474 . x}$

Pastor, Lubos \& Stambaugh, Robert (2012). Are stock really less volatile in the long run? The Journal of Finance 67(2), 431-478. https://doi.org/10.1111/j.1540-6261.2012.01722.x

Pettenuzzo, Davide \& Ravazzolo, Francesco (2016). Optimal Portfolio Choice Under Decision-Based Model Combinations. Journal of Applied Econometrics 31(7), 13121332. https://doi.org/10.1002/jae.2502

Ponka, Harri (2017). Predicting the direction of US stock markets using industry returns. Empirical Economics 52, 1451-1480. https://doi.org/10.1007/s00181-016-1098-0

Rapach, David E., Strauss, Jack K., \& Guofou, Zhou (2010). Out-f-sample equity premium prediction: combination forecasts and links to the real economy. Review of Financial Studies 23(2), 821-862. https://doi.org/10.1093/rfs/hhp063

Rapach, David E., Strauss, Jack K., Tu Jun, \& Guofou, Zhou (2019). Industry Return Predictability: A Machine Learning Approach. The Journal of Financial Data Science 1 (3), 9-28. https://doi.org/10.3905/jfds.2019.1.3.009

Sander, Magnus (2018). Market timing over the business cycle. Journal of Empirical Finance 46, 130-145. https://doi.org/10.1016/i.jempfin.2017.12.002

Silva, Nuno (2018). Industry-based equity premium forecasts. Studies in Economics and Finance 35(3), 426-440. https://doi.org/10.1108/SEF-10-2016-0256

Tse, Yiuman (2015). Do industries lead stock markets? A reexamination. Journal of Empirical Finance 34, 195-203. https://doi.org/10.1016/i.jempfin.2015.10.003

Zhu, Xiaoneng, \& Zhu, Jie (2013). Predicting stock returns: A regime-switching combination approach and economic links. Journal of Banking \& Finance 37(11), 41204133. https://doi.org/10.1016/j.jbankfin.2013.07.016 